\title{
Foot and Ankle Muscles Activation and Plantar Sensory Deficit in Leprosy and Its Implication to Foot Deformity and Walking Capacity
}

\author{
Fitri Anestherita*, Ibrahim Agung, Nelfidayani Nelfidayani, Andri Setiawan Kokok, Johanes Putra \\ Physical Medicine and Rehabilitation Department, Faculty of Medicine, Universitas Indonesia, Cipto Mangunkusumo Hospital, \\ Jakarta, Indonesia \\ Email: *fitri.anestherita@gmail.com
}

How to cite this paper: Anestherita, F., Agung, I., Nelfidayani, N., Kokok, A.S. and Putra, J. (2021) Foot and Ankle Muscles Activation and Plantar Sensory Deficit in Leprosy and Its Implication to Foot Deformity and Walking Capacity. Open Journal of Therapy and Rehabilitation, 9, 123-131. https://doi.org/10.4236/ojtr.2021.94010

Received: September 14, 2021

Accepted: November 5, 2021

Published: November 8, 2021

Copyright $\odot 2021$ by author(s) and Scientific Research Publishing Inc. This work is licensed under the Creative Commons Attribution International License (CC BY 4.0).

http://creativecommons.org/licenses/by/4.0/

\begin{abstract}
Objective: To observe extrinsic foot muscle activity ratio and sensory disturbance in Leprosy and its implication to foot deformity and walking capacity. Design: Cross sectional study in Singkawang, West Kalimantan. Materials and Methods: Thirty-three leprosy patients without walking aids and/or orthotic prosthetic were enrolled using consecutive sampling. Foot deformity score was calculated and muscle activity was measured using surface EMG. Muscle activation ratio was calculated in Tibialis anterior-to-Gastrocnemius (TA/GA) and Tibialis Anterior-to-Peroneal (TA/PE). Walking capacity was assessed using Timed up and Go test. Results: Significant differences of foot ulcer ( $p=0.001)$ and foot deformities ( $p=0.001)$ were found in plantar sensory deficit group. There was strong correlation between foot deformities and decreased TA/GA ratio $(\mathrm{p}=0.001, \mathrm{r}=-0.787)$ and decreased TA/PE ratio $(\mathrm{p}$ $=0.001, r=-0.663)$. There were significant differences of TA/GA ratio $(p=$ $0.00)$ and TA/PE ratio $(\mathrm{p}=0.09)$ based on the foot ulcer, and no significant difference of Timed Up and Go Test result within plantar sensory deficit group $(p=0.427)$. No significant correlation was found between walking capacity and TA/GA ratio $(\mathrm{p}=0.055)$, and TA/PE ratio $(\mathrm{p}=0.165)$. Conclusion: Plantar sensory deficit and decreased extrinsic muscle activation ratio during gait had been proven to affect foot impairment, but have not been proven to inhibit walking capacity.
\end{abstract}

\section{Keywords}

Leprosy, Foot Impairment, Walking Capacity, Muscle Activity

\section{Introduction}

Leprosy, also known as Hansen's disease, is a chronic infectious disease caused 
by Mycobacterium leprae [1] [2] [3]. Leprosy is a widespread disease in Indonesia and worldwide. The prevalence of leprosy in Indonesia in 2017 was 0.7 cases/10.000 population, and the new case finding rate was 6.08 cases/100.000 population [4]. Nerve damage is the most prominent feature of the disease, causing most of the disability suffered by the patient. Posterior tibial and common peroneal nerve is commonly involved in Leprosy [5]. The posterior tibial and peroneal neuropathy in leprosy may result in sensory loss and muscle weakness causing gait abnormalities. Previous study conducted by Frederik et al., showed that there was an increase in foot pressure especially in the metatarsal head section in leprosy patients. It was associated with peripheral neuropathy and toe deformities. Impaired nerve function on posterior tibial nerve and common peroneal nerve affects foot function and walking. It can cause callus, foot deformities, and decrease muscle strength, which can lead to increased foot pressure [6]. The rise of foot pressure on pressure intolerant areas in the foot will increase the risk of pressure ulcer. The biomechanical alterations observed in patients with leprosy that derived from amyotrophy, muscle weakness, and deformities contribute directly to the breakdown of the bones in the foot. Among the deformities and disorders that affect patients with leprosy, weakness of dorsal flexors (tibialis anterior) and evertors (the posterior tibiae and peroneal, respectively) are the most important. Many patients develop foot impairments and are at risk of foot ulceration even if they are treated with medications. Foot ulceration is a major health and social problem, which may lead to amputation and disability in leprosy patients [7]. The objective of this study is to evaluate extrinsic foot muscle activation pattern during gait and to determine its correlation with foot deformities and walking capacity in leprosy patients.

\section{Material and Methods}

This study was conducted at Alverno Hospital, Singkawang, West Kalimantan, Indonesia. Thirty-three inpatient and outpatient cases of leprosy were included in this study using consecutive sampling method. The inclusion criteria were patients who were able to walk without walking aids and/or orthotic prosthetic, both of the gender, and patients of all type and duration of Leprosy. We excluded patients who rejected to participate in this study, and those who were allergic to the electrode used in this study.

Sensory testing was performed using Semmes-Weinstein graded monofilaments, by placing the monofilaments on ten points on the feet to diagnose damage to the posterior tibial nerve. The test sites included the pressure-prone forefoot area, the lateral border of the foot, and the heel. The examiner instructed the patient to respond by saying "Yes" or "Touch" when the stimuli are felt. If the patient did not feel the monofilament, the test was repeated up to three times on that area. If the patient could not feel the sensation in more than two areas during the examination, this indicated a loss of protective sensation (LOPS) on the feet [5]. 
The measurement of extrinsic foot muscle activation during gait was done using surface EMG Neurotrac Myoplus Pro 4 with and electrode the size of $5 \times 5$ $\mathrm{cm}$. The placement of the electrode is determined according to the SENIAM recommendation [8]. Prior to EMG examination, the skin was cleaned using $70 \%$ alcohol. The electrodes were placed on the anterior tibial muscle at $1 / 3$ proximal between the tip of the fibula and the tip of the medial malleolus, then the patient was asked to walk on their comfortable walking speed. After that, the Maximum Voluntary Contraction (MVC) data on the EMG tool was documented. The same protocol was performed on the assessment of gastrocnemius and peroneal muscle. The electrode is placed at $1 / 3$ proximal between the head of the fibula and the heel for gastrocnemius lateral and on the most prominent bulge of the muscle for gastrocnemius medialis muscle. Meanwhile, to measure the activation of the peroneal muscle, the electrode is placed at 1/4 proximal between the tip of the head of the fibula to the tip of the lateral malleolus.

In this study, foot deformities were measured by scoring the presence of hammer/claw toes, hallux valgus, absorption/amputation, pes cavus/planus, ankle varus/valgus (all were observed in weight-bearing position), prominent metatarsal head (by palpation) and end-stage neuro-osteoarthropathy (also called the neuropathic bone disorganization). Hammer/claw toes were only scored if significant absorption of toes was not present at the same time. A score of one was given for each deformity present on either one or both feet, except for amputation, which was scored as one for below ankle amputation and two for above ankle amputation (indicating more serious foot impairment). A foot deformity sum-score was obtained by summing up the scores of all the deformities (range 0 - 8) [9].

The ability to walk (i.e. walking capacity) was assessed by using Time Up and Go Test (TUG). The patients started in a seated position, then patients were asked to follow instructions given by the examiner. Patients were asked to stand up, walk three meters, turn around, walk back to the chair, and sit down. The time was measured starting from standing up until the patient sit back on the chair [10].

Patient's demographic and clinical characteristics were analyzed using descriptive statistics. Chi-square test with $95 \%$ confidence interval was used for statistical evaluation. A p value of $<0.05$ was considered significant. Independent t-tests were used to compare groups mean for the dichotomous determinants. Pearson's correlation coefficients were used to investigate associations between continuous determinants and outcome measurements. A point bi-serial correlation coefficient was performed to quantify the relationship between dichotomous determinants and the outcome measurements.

\section{Results}

Demographic and characteristics of the subjects are described in Table 1 . Thirty-three patients were enrolled in this study (26 males and 7 females) with age 
ranging from 15 - 69 years old. The median age of the subject was 48 years old. All subjects were able to walk without any ambulatory aid and/or orthotic prosthetic, and none of them wore adjusted footwear in their daily life.

Various foot deformities were found in the subjects (described in Table 2). Extrinsic foot muscle activation during gait was also measured. MVC score from extrinsic foot muscle examination had various values. Tibialis anterior and gastrocnemius muscle had a mean value of $18.84 \pm 6.53$ and $25.51 \pm 6.27$, respectively. Meanwhile, peroneal muscles had a mean value of $19.51+6.50$.

Table 1. Subjects demographic and clinical characteristic.

\begin{tabular}{|c|c|}
\hline Characteristic & n (\%) \\
\hline \multicolumn{2}{|l|}{ Age (years) } \\
\hline$<40$ & $11(33.3)$ \\
\hline $40-59$ & $13(39.4)$ \\
\hline$>60$ & $9(27.3)$ \\
\hline \multicolumn{2}{|l|}{ Gender } \\
\hline Male & $26(78.8)$ \\
\hline Female & $7(21.2)$ \\
\hline \multicolumn{2}{|l|}{ Occupation } \\
\hline Indoor activity & $9(27.3)$ \\
\hline Outdoor activity & $21(63.6)$ \\
\hline Unemployed & $3(9.1)$ \\
\hline \multicolumn{2}{|l|}{ Level of Education } \\
\hline No formal education & $7(21.2)$ \\
\hline Elementary School graduate & $14(42,4)$ \\
\hline Middle School graduate & $4(12.1)$ \\
\hline High School graduate & $6(18.2)$ \\
\hline Bachelor/Master Degree & $2(6.1)$ \\
\hline \multicolumn{2}{|l|}{ Leprosy type } \\
\hline Multibacillary & $23(69.7)$ \\
\hline Paucibacillary & $7(21.2)$ \\
\hline No data & $3(9.1)$ \\
\hline \multicolumn{2}{|l|}{ Duration of illness } \\
\hline$<5$ years & $13(39.4)$ \\
\hline $5-10$ years & $3(9.1)$ \\
\hline$>10$ years & $13(39.4)$ \\
\hline
\end{tabular}


Table 2. Plantar sensory deficit and extrinsic foot muscle activation during gait, and walking capacity.

\begin{tabular}{|c|c|}
\hline Variables & \\
\hline \multicolumn{2}{|l|}{ Plantar Sensory deficit, n (\%) } \\
\hline Yes & $21(63.6)$ \\
\hline No & $12(36.4)$ \\
\hline \multicolumn{2}{|l|}{ Extrinsic Foot Muscle Activation during Gait } \\
\hline Tibialis anterior muscle, mean $\pm \mathrm{SD}$ & $18.84 \pm 6.53$ \\
\hline Peroneal Muscles, mean \pm SD & $19.51 \pm 6.50$ \\
\hline Gastrocnemius muscles, mean $\pm \mathrm{SD}$ & $25.51 \pm 6.27$ \\
\hline Tibialis Anterior/Gastrocnemius (TA/GA) Ratio, median (min-max) & $0.67(0.37-2.49)$ \\
\hline Tibialis Anterior/Peroneus (TA/PE) Ratio, median (min-max) & $0.97(0.66-1.33)$ \\
\hline \multicolumn{2}{|l|}{ Foot deformities Score, median (min-max) } \\
\hline Hammer/claw toes, $\mathrm{n}(\%)$ & $23(23.23)$ \\
\hline Hallux valgus, n (\%) & $7(7.07)$ \\
\hline Absorption/amputation, n (\%) & $7(7.07)$ \\
\hline Pes cavus/planus, $\mathrm{n}(\%)$ & $22(22.22)$ \\
\hline Ankle varus/valgus, $\mathrm{n}(\%)$ & $25(25.25)$ \\
\hline Prominent metatarsal head, $\mathrm{n}(\%)$ & $7(7.07)$ \\
\hline Neuropathic bone disorganization, $\mathrm{n}(\%)$ & $7(7.07)$ \\
\hline \multicolumn{2}{|l|}{ Foot ulcer, n (\%) } \\
\hline Yes & $12(36.4)$ \\
\hline No & $21(63.6)$ \\
\hline Timed Up and Go test, median (min-max) & $9.10(5.58-15.20)$ \\
\hline
\end{tabular}

(TA/GA): Tibialis Anterior/Gastrocnemius Ratio. (TA/PE): Tibialis Anterior/Peroneus Ratio.

Table 3 shows significant differences of presence of foot ulcer and foot deformities between plantar sensory deficit group ( $\mathrm{p}=0.001$ and $\mathrm{p}=0.001$ respectively). There was no significant difference of Timed $U p$ and Go Test Result within plantar sensory deficit group $(\mathrm{p}=0.427)$.

Muscle activation ratio during gait was calculated between tibialis anterior and gastrocnemius muscle (TA/GA ratio), and also between tibialis anterior and peroneus muscle (TA/PE ratio). There were strong significant correlations between decreased TA/GA ratio with foot deformities $(p=0.001, r=-0.787)$ and between decreased TA/PE ratio with foot deformities $(p=0.001, r=-0.663)$, but no significant correlation was found between TA/GA ratio and TA/PE ratio with walking capacity ( $\mathrm{p}=0.055$ and $\mathrm{p}=0.165$ respectively), as shown in Table 4 . In Table 5, it shows that there were also significant differences between decreased TA/GA ratio and presence of foot ulcer $(\mathrm{p}=0.00)$, and also between decreased $\mathrm{TA} / \mathrm{PE}$ ratio and presence of foot ulcer $(\mathrm{p}=0.09)$. 
Table 3. Foot deformities, foot ulcer, and walking capacity based on plantar sensory deficit.

\begin{tabular}{|c|c|c|c|c|c|c|c|}
\hline \multirow{2}{*}{ Variables } & \multirow{2}{*}{$\begin{array}{l}\text { Foot Deformities, } \\
\text { Median (min-max) }\end{array}$} & \multirow{2}{*}{$\mathrm{p}$} & \multicolumn{2}{|c|}{ Foot Ulcer n (\%) } & \multirow{2}{*}{$\mathrm{p}$} & \multirow{2}{*}{$\begin{array}{l}\text { TUG Median } \\
\text { (min-max) }\end{array}$} & \multirow{2}{*}{$\mathrm{p}$} \\
\hline & & & Yes & No & & & \\
\hline \multicolumn{8}{|c|}{ Plantar Sensory deficit } \\
\hline Yes & $3(1-7)$ & $0.001^{1}$ & $12(57.1)$ & $9(42.9)$ & 0.001 & $9.67(8.12-14.28)$ & 0.427 \\
\hline No & $0.5(0-2)$ & & $0(0)$ & $12(100)$ & & $8.68(5.58-15.20)$ & \\
\hline
\end{tabular}

${ }^{1}$ The significance level is 0.05 . TUG: Timed Up and Go Test.

Table 4. Correlation between muscle activation during gait with foot deformities and walking capacity.

\begin{tabular}{ccccc}
\hline \multirow{2}{*}{$\begin{array}{c}\text { Extrinsic Foot Muscle } \\
\text { Activation during Gait }\end{array}$} & \multicolumn{2}{c}{ Foot Deformities } & \multicolumn{2}{c}{ TUG } \\
\cline { 2 - 5 } & Correlation Coefficient & $\mathrm{p}$ & Correlation Coefficient & $\mathrm{p}$ \\
\hline TA/GA Ratio & $-0.787^{\star *}$ & 0.001 & 0.055 & 0.055 \\
TA/PE Ratio & $-0.663^{\star *}$ & 0.001 & -0.247 & 0.165 \\
\hline
\end{tabular}

** Correlation is significant at the 0.01 level (2-tailed). (TA/GA): Tibialis Anterior/Gastrocnemius Ratio. (TA/PE): Tibialis Anterior/Peroneus Ratio. (TUG): Timed Up and Go Test

Table 5. Pressure ulcer incidence based on muscle activation during gait.

\begin{tabular}{|c|c|c|c|}
\hline \multirow{2}{*}{ Muscle Activation Ratio During Gait } & \multicolumn{2}{|c|}{ Pressure Ulcer } & \multirow{2}{*}{$\mathrm{p}$} \\
\hline & Yes & No & \\
\hline $\begin{array}{c}\text { TA/GA Ratio } \\
\text { median (min-max) }\end{array}$ & $\begin{array}{c}0.49 \\
(0.37-0.68)\end{array}$ & $\begin{array}{c}0.85 \\
(0.62-2.49)\end{array}$ & $0.001^{1}$ \\
\hline $\begin{array}{c}\text { TA/PE Ratio } \\
\text { median (min-max) }\end{array}$ & $\begin{array}{c}0.86 \\
(0.80-1.21)\end{array}$ & $\begin{array}{c}1.00 \\
(0.66-1.33)\end{array}$ & $0.009^{1}$ \\
\hline
\end{tabular}

${ }^{1}$ The significance level is 0.05. (TA/GA): Tibialis Anterior/Gastrocnemius Ratio. (TA/PE): Tibialis Anterior/Peroneus Ratio.

\section{Discussion}

In this study, we found that the occurrence of foot deformity and a pressure ulcer on the plantar is significantly higher on subject group with plantar sensory deficit. The sensory nerve damage causes loss of sensory functions that protect the foot against environmental hazards, and eventually results in foot deformation. Furthermore, secondary infections may cause loss of tissue, causing fingers become shortened and deformed, as the cartilage is absorbed. However, plantar sensory deficit had not been proven to affect patient's walking capacity. The patient's walking capacity measured by the TUG is affected more by its proprioceptive, motoric, and vestibular function, so the examination of the tactile sensory in this study cannot depict the damage on all sensory components that can affect patient's walking capacity.

The impairment of the deep branch of the lateral popliteal (common peroneal) nerve leads to weakness of the tibialis anterior muscle (TA), extensor hallucis longus, extensor digitorum longus, and peroneus tertius muscles. The peroneus longus and brevis will be affected if the superficial branch is affected, 
leading to loss of ankle dorsiflexion, foot eversion, and toe extension [5]. During gait, TA maintains dorsiflexion of the ankle in preparation for heel strike by contracting eccentrically to control the lowering of the foot after initial contact [11]. This study found significant correlation between a decreased TA/GA ratio with the occurrence of foot deformities and pressure ulcer. The decrease in the dorsiflexor's ability causes an increase in pressure around the forefoot area and increases the risk of foot injury because inadequate foot clearance. The increased foot pressure on pressure intolerant areas on the foot will increase the risk of pressure ulcer.

As an invertor of the foot, TA muscle help controlling the eversion during stance phase. TA is well placed to oppose the passive pronation movement (combination of dorsiflexion, eversion and abduction) that tends to occur at heel strike and stance phase [11]. In this study, we also found a strong correlation between a decreased TA/PE ratio with foot deformities and a higher occurrence of foot ulcer on the subjects with a lower TA/PE ratio. A decreased ratio of tibialis anterior in comparison to peroneal will cause over pronated foot, which is a common deformity in this population. There were $22.22 \%$ of subjects that has pronated foot/pes planus. An increased plantar pressure distribution will occur on the over pronated foot where the pressure in the talocalcaneonavicular joint is higher, which increases the risk of a plantar ulcer on that area.

This study could not find the relationship between the TA/GA ratio and TA/ PE ratio with walking capacity. This showed that the decrease muscle activation ratio during gait between Tibialis anterior-to-Gastrocnemius (TA/GA), and also between Tibialis Anterior-to-Peroneal (TA/PE) does not depict the dynamic stability in the Time Up and Go test. When a person is walking, the stabilization of the trunk and lower extremities that will affect walking capacity is controlled by a lot of factors, which include mechanical factors (including mass, center of gravity location and base of support effect on body balance), postural reflex, and the ability of the trunk, pelvis, and lower extremity stabilizer muscles. Slim et al in their study found that various foot impairments independently contributed to reduced walking capacity of leprosy patients, but in this study, we did not analyze the association between foot impairments and walking capacity [9].

Our results indicated that the neuropathy complication on leprosy that caused weakness in dorsiflexor control and ankle eversion could lead to increased foot deformity and pressure ulcer incidence. Therefore, preventive measures against the damage of the foot structure should involve the strengthening of the extrinsic muscles, mainly the ankle dorsiflexor and invertor muscles.

It is important to note that this study only used the sEMG to evaluate superficial extrinsic muscles. Involvement of peroneal and tibial nerves in lepromatous leprosy commonly results in weakness and wasting of the intrinsic foot muscles as well, especially the extensor digitorum brevis, as well as the anterior tibial group and the calf muscles. Atrophy of the intrinsic foot muscles may lead to clawing of toes and contribute to foot deformity by reducing soft tissue resilien- 
cy on the plantar surface [12]. Along with the appearance of claw toes, the fall of the transverse arch of the foot exposes the metatarsal heads to high plantar pressures and may affect the foot because of altered sensitivity [13]. Increased plantar pressure in this area is thought to be one of the risk factors for foot ulceration in people with leprosy. The limitation of this study was that it did not keep track of each subject's weight and daily walking time, which were important factors in the formation of pressure ulcer on the foot.

\section{Conclusion}

In this study, plantar sensory deficit and the decrease muscle activation ratio during gait between Tibialis anterior-to-Gastrocnemius, and also between Tibialis Anterior-to-Peroneal have been proven to be the factors that can affect the presence of foot impairment, but have not been proven to inhibit the subject's walking capacity.

\section{Acknowledgements}

The authors would like to thank Katamataku team for research collaboration project and Alverno Hospital for their support to facilitate this project and recruiting the Leprosy patients.

\section{Ethical Statement}

This study had a cross-sectional study design. It was approved by the local review board and the Ethics Committee (Ethics Committee of University of Indonesia, Jakarta ref. number 19-05-0633).

\section{Informed Consent}

All patients enrolled in this study have been informed about the study and have given their consent to participate and to publish the data on scientific journals.

\section{Funding}

This study was self-funded.

\section{Conflicts of Interest}

The authors declare no conflicts of interest regarding the publication of this paper.

\section{References}

[1] Nascimento, O.J.M. (2013) Leprosy Neuropathy: Clinical Presentations. Arquivos de Neuro-Psiquiatria, 71, 661-666. https://doi.org/10.1590/0004-282X20130146

[2] Kumar, V. (2017) Emerging Concept on Peripheral Nerve Damage in Leprosy. International Journal of Research Studies in Medical and Health Sciences, 2, 8-18.

[3] Kundakci, N. and Erdem, C. (2019) Leprosy: A Great Imitator. Clinics in Dermatology, 37, 200-212. https://doi.org/10.1016/j.clindermatol.2019.01.002 
[4] Kemenkes, R.I. (2018) Hapuskan Stigma dan Diskriminasi terhadap Kusta. InfoDatin Pusat Data dan Informasi Kementrian Kesehatan RI 2018.

https://www.kemkes.go.id/article/view/19011500011/hapuskan-stigma-dan-diskrim inasi-terhadap-kusta.html

[5] Paul, M.S.K., Kumar, D.P. and Govindasamy, K. (2018) Physical Rehabilitation in Leprosy. In: Scollard, D.M. and Gillis, T.P., Eds., The International Textbook of Leprosy (13). American Leprosy Mission, Greenville.

https://www.internationaltextbookofleprosy.org/chapter/physical-rehabilitation\#int roduction $\% 0 \mathrm{~A}$

[6] Slim, F.J., van Schie, C.H., Keukenkamp, R, Faber, W.R. and Nollet, F. (2012) Increased Plantar Foot Pressure in Persons Affected by Leprosy. Gait \& Posture, 35, 218-224. https://doi.org/10.1016/j.gaitpost.2011.09.010

[7] Vijayan, J. and Einar, W.-S. (2018) Neurological Manifestations of Leprosy. In: Scollard, D.M. and Gillis, T.P., Eds., The International Textbook of Leprosy (13). American Leprosy Mission, Greenville.

https://internationaltextbookofleprosy.org/chapter/neurological-manifestations-lep rosy

[8] SENIAM. Recommendations for Sensor Locations in Lower Leg or Foot Muscles. http://seniam.org/lowerleg location.htm

[9] Slim, F.J., Keukenkamp, R., Van Schie, C.H., Faber, W.R. and Nollet, F. (2011) Foot Impairments and Limitations in Walking Activities in People Affected by Leprosy. Journal of Rehabilitation Medicine, 43, 32-38. https://doi.org/10.2340/16501977-0625

[10] Picone, EN. (2013) The Timed Up and Go Test. American Journal of Nursing, 113, 56-59. https://doi.org/10.1097/01.NAJ.0000427881.33418.cb

[11] Qaqish, J. and Mclean, S. (2010) Foot Type and Tibialis Anterior Muscle Activity during the Stance Phase of Gait: A Pilot Study. International Journal of Physiotherapy and Rehabilitation, 1, 19-29.

[12] Swift, T.R., Hackett, E.R., Shipley, D.E. and Miner, K.M. (1973) The Peroneal and Tibial Nerves in Lepromatous Leprosy. Clinical and Electrophysiologic Observations. International Journal of Leprosy and Other Mycobacterial Diseases, 41, 25-34.

[13] Cordeiro, T.L., Frade, M.A.C., Barros, A.R.S.B. and Foss, N.T. (2014) Baropodometric Evaluations and Sensitivity Alterations in Plantar Ulcer Formation in Leprosy. The International Journal of Lower Extremity Wounds, 13, 110-115. https://doi.org/10.1177/1534734614536034 